\title{
Autoría Y PARTICIPACIÓN EN EL DELITO DE PRODUCCIÓN DE MATERIAL PORNOGRÁFICO INFANTO-JUVENIL ${ }^{*}$
}

[Perpetrating and Participating in the Crime of Production of Child-Juvenile Pornographic Material]

\section{Luis Rodríguez CollaO** \\ Pontificia Universidad Católica de Valparaíso, Chile}

Daniel Polanco Valdés***

\begin{abstract}
RESUMEN
El artículo examina, dogmática y positivamente, las distintas formas que puede asumir la intervención de un sujeto en el delito de producción de material pornográfico infanto-juvenil. Indaga el sentido y el alcance de la conducta que constituye aquel delito y las particularidades que asumen la autoría directa, la autoría mediata y la coautoría. Plantea, asimismo, la admisibilidad de las distintas formas de intervención secundaria (participación) y expone las principales
\end{abstract}

\section{ABSTRACT}

This article examines, from a dogmatic and positive standpoint, different ways in which an individual can be involved in the crime of producing childjuvenile pornographic material. We seek into the sense and the scope of the behavior that constitutes the crime and the specific features posed by the direct perpetration, command responsibility and accomplice responsibility. Likewise, we put forward the admissibility of the different ways of secondary involvement

RECIBIDO el 3 de septiembre y ACEPTADO el 7 de diciembre de 2015

* Trabajo generado en el marco del proyecto de investigación FONDECYT 1121195 , ejecutado por el Departamento de Derecho Penal y Derecho Procesal Penal de la Escuela de Derecho de la Pontificia Universidad Católica de Valparaíso.

** Profesor titular de derecho penal en la Pontificia Universidad Católica de Valparaíso.

*** Ayudante de investigación en el Departamento de Derecho Penal y Derecho Procesal Penal de la Escuela de Derecho de la Pontificia Universidad Católica de Valparaíso. 
dificultades que puede traer consigo su aplicación.

\section{Palabras clave}

Pornografía infantil - Producción de material pornográfico - Autoría y participación en el delito de producción de material pornográfico infanto-juvenil. (participation) and set forth the main difficulties that its application may entail.

\section{KEYWORDS}

Child Pornography - Production of Pornographic Material - Authoring and Participation in the Crime of Production of Child-Juvenile Pornographic Material

\section{INTRODUCCIÓN}

Las disposiciones que el Código Penal chileno destina a tratar el tema de la autoría y la participación siguen planteando una serie de interrogantes, especialmente en lo que respecta a los comportamientos que quedan incluidos en cada una de las categorías de intervinientes que establecen los artículos 15, 16 y 17 de dicho texto normativo; y las dudas, por cierto, se acrecientan cuando tales disposiciones deben ser aplicadas a tipos penales que utilizan una terminología vaga e imprecisa para describir las conductas que ellos pretenden captar.

Es lo que ocurre, precisamente, con el delito de producción de material pornográfico infanto-juvenil, contemplado en el artículo 366 quinquies CPen., cuya conducta aparece expresada con el verbo "participar" en la producción de dicho material, generando de ese modo un importante grado de confusión acerca de los comportamientos que esa fórmula discursiva comprende.

En concreto, este trabajo se propone examinar las dificultades interpretativas que plantea la figura de producción de material pornográfico infanto-juvenil en materia de autoría y participación. Para el logro de este objetivo, desde luego, resulta indispensable examinar el origen, los fundamentos y la estructura interna de la figura, como así también adentrarse en el contenido prescriptivo de las disposiciones que el Código Penal chileno destina a las diversas formas de intervenir en un delito.

No se trata, en consecuencia, de examinar esta figura delictiva desde una perspectiva de conjunto, ni de proponer una solución a todas las dificultades que ella plantea. Así se explica que el trabajo no desarrolle otros temas -como el concepto de material pornográfico, el iter criminis o las relaciones concursales que se dan entre éste y otros delitos- los cuales, pese a revestir una gran trascendencia, no tienen conexión directa con el tema central de esta exposición. 


\section{ASPECTOS GENERALES DEL DELITO DE PRODUCCIÓN DE MATERIAL PORNOGRÁFICO INFANTO-JUVENIL}

\section{Evolución histórica.}

La producción de pornografía representativa de menores de edad no era un suceso típico en el texto original del Código Penal chileno. El único delito que captaba una conducta relativamente próxima a aquélla era el contemplado en el artículo 374 de dicho texto legal, que hasta hoy sanciona la venta, la distribución y la exhibición de materiales contrarios a las buenas costumbres, pero sin hacer distinción acerca de la edad de las personas que el autor utiliza para ello.

El precedente legislativo de la figura que aquí analizaremos es el artículo 366 quater incorporado por la Ley $\mathrm{N}^{\circ} 19.617$, de 12 de julio de 1999, cuyo contenido incluía en su momento, y aún lo hace, una serie de conductas constitutivas de lo que se entiende como abuso sexual impropio o indirecto, pero en lo relevante para este estudio sancionaba el hecho de "emplear a un menor de doce años en la producción de material pornográfico" 1 .

La norma citada precedentemente fue derogada por el artículo 34 de la Ley $N^{\circ} 19.846$, sobre Calificación de la Producción Cinematográfica, publicada el 4 de enero de 2003; pero un año más tarde, el 14 de enero de 2004, se publicó la Ley $\mathrm{N}^{\circ} 19.927$, que restableció el delito aquí estudiado, ubicándolo esta vez en el nuevo 366 quinquies, locación que conserva hasta hoy, con un núcleo conductual inalterado desde aquella ocasión, agregando una definición de pornografía infantil, que fue tomada literalmente del Protocolo Facultativo de la Convención sobre Derechos del Niño, relativo a la venta de niños, a la prostitución infantil y a la utilización de menores en la pornografía.

Finalmente, la Ley $\mathrm{N}^{\circ}$ 20.526, publicada el 13 de agosto de 2011, incorporó por primera vez lo que en otros países se denomina "grooming" o "child grooming" (art. 366 quater inciso segundo) y complementó la descripción del objeto material del delito de producción de material pornográfico para dar cabida a cualquier representación de un menor en que se emplee su voz o imagen, con fines primordialmente sexuales.

\section{Bien jurídico protegido.}

Las opiniones doctrinales y jurisprudenciales se encuentran profunda-

${ }^{1}$ Sobre la motivación político-internacional que tuvo el Estado de Chile para incorporar este delito en nuestra legislación, KünSEMuller, Carlos, Derecho penal y política criminal (Santiago, LegalPublishing, 2012), pp. 513 ss. 
mente divididas en lo que concierne a la determinación del bien jurídico protegido por el delito de producción de material pornográfico infantojuvenil. Un sector de la doctrina y de la jurisprudencia, en efecto, sostiene que lo protegido por este delito es la "indemnidad sexual", entendiendo por tal, el derecho de las personas a no verse involucradas en un contexto sexual, en atención al daño físico, psíquico o emocional que tal experiencia puede ocasionar en el común de los seres humanos².

Otra corriente de opinión sostiene que el bien jurídico protegido por este delito es la "libertad sexual", entendida en su sentido negativo, esto es, como el derecho de la persona a no verse involucrada, sin su consentimiento, en un contexto sexual por terceros ${ }^{3}$. Este punto de vista, como lo ha hecho presente Caruso Fontán, presupone la aceptación de un concepto amplio de libertad sexual, que incluya las valoraciones que normalmente se plantean como parte del concepto de "indemnidad" o "incolumidad"4.

Hay, también, quienes armonizan las nociones de libertad e indemnidad, afirmando que el bien jurídico protegido depende de la edad de la víctima, ya que si ésta es menor de catorce años, lo tutelado es la indemnidad sexual; en cambio, si la víctima es menor de edad, pero mayor de catorce años, el bien jurídico protegido sería la libertad sexual, puesto que el legislador ha reconocido a esos menores la capacidad de autodeterminarse sexualmente .

${ }^{2}$ En España son de esta opinión, Aguado Lopez, S., Delitos contra la libertad e indemnidad sexuales, en Borx ReIg (director), Derecho penal. Parte especial (Madrid, Iustel, 2010), p. 391; FernándeZ Teruelo, Javier, Derecho penal e internet. Especial consideración de los delitos que afecta a jóvenes y adolescentes (Valladolid, Lex Nova, 2011), p. 116. Este es también el criterio ampliamente mayoritario en la jurisprudencia española, como lo ponen de manifiesto las sentencias $\mathrm{N}^{\circ} 72$, de 26 de febrero de 2009, de la Audiencia Provincial de Guipúzcoa; № 37, de 9 de julio de 2008, de la Audiencia Provincial de Madrid, y No 8, de 29 de enero de 2009, de la Audiencia Provincial de Palencia. En Chile, defiende este planteamiento Garrido MonTt, Mario, Derecho penal. Parte especial ( $4^{a}$ edición, Santiago, Editorial Jurídica de Chile, 2010), III, p. 338. A nivel jurisprudencial lo acoge la sentencia de la Corte de Apelaciones de Concepción, de 12 de mayo de 2006 (rol N² 201-2006).

${ }^{3}$ Así, Aguilar Aranela, Cristían, Delitos sexuales (2a edición, Santiago, Editorial Metropolitana, 2012), p. 163; OxMAN VILCHES, Nicolás, Libertad sexual y Estado de Derecho en Chile (Librotecnia, Santiago, 2007), pp. 156-157. En la jurisprudencia española se aprecia una adopción de este bien jurídico pero en el contexto de una mixtura conceptual con otros valores no vinculados con el ámbito sexual, véase en ese sentido la sentencia de la Audiencia Provincial de Pontevedra, Sección 2a, Sentencia de 30 de octubre de 2006, rec. 24/2006.

${ }^{4}$ Caruso Fontán, María Viviana, Nuevas perspectivas sobre los delitos contra la libertad sexual (Tirant Lo Blanch, Valencia, 2011), p. 178.

${ }^{5}$ En nuestro país, Politoff, Sergio - Matus Acuña, Jean Pierre - Ramírez Guz- 
De otro lado, no son pocos los autores que entienden la producción de material pornográfico infanto-juvenil como un delito pluriofensivo, cual lo hace, entre nosotros, Carnevali Rodríguez, al afirmar que, además de la libertad y la indemnidad sexual, resultaría afectado el derecho a la propia imagen del menor de edad, y su honra ${ }^{6}$. En esta misma línea, algunos recurren a la noción de "integridad sexual", un concepto dotado de un campo semántico muy amplio, que permitiría abarcar todas las valoraciones que subyacen a los delitos que forman este sector del ordenamiento punitivo ${ }^{7}$.

En nuestro concepto, la determinación del bien jurídico protegido por el delito de producción de material pornográfico infanto-juvenil ha de tener en cuenta, fundamentalmente, la ubicación sistemática de esta figura. En efecto, ella se encuentra dentro del título $7^{\circ}$, del libro II CPen., cuyo epígrafe es "Crímenes y delitos contra el orden de las familias, contra la moralidad pública y contra la integridad sexual". De modo más

MÁn, María Cecilia, Lecciones de derecho penal chileno. Parte especial (2a edición, Santiago, Editorial Jurídica de Chile, 2005) p. 279; De La Fuente Jiménez, Claudia, Delitos de pornografía infantil (Santiago, LegalPublishing, 2008), p. 107. En el ámbito doctrinal español, exponen esta solución Serrano Gómez, Alfonso - SERraNo Maíllo, Alfonso, Derecho penal. Parte especial (16a edición, Madrid, Dykinson, 2011), p. 252; De La Rosa Cortina, José Miguel, Los delitos de pornografía infantil. Aspectos penales, procesales y criminológicos (Valencia, Tirant Lo Blanch, 2011), pp. 52-60. Cabe hacer la prevención de que en este último caso, la distinción no sólo gira en base a la edad de la víctima sino que de manera conjunta con el conocimiento o conciencia de estar siendo utilizado en la producción de material pornográfico.

${ }^{6}$ Carnevali Rodríguez, Raúl, Algunas precisiones respecto de los delitos de producción de material pornográfico infantil, de favorecimiento de prostitución de menores y de obtención de servicios sexuales, Informe en derecho $\mathrm{N}^{\circ} 2$ (Defensoría Penal Pública, Departamento de Estudios, Santiago, 2012), pp. 6-10. Cfr. En el derecho español por su parte, son comunes las referencias doctrinales a valores no sexuales como objeto de protección por la norma análoga en el Código Penal de ese país, así ÚBEDA DE LOS CoBos, Julio, La persecución de la pornografía infantil. Problemas relacionados con su distribución por Internet, en La Ley Penal, 37, Sección Estudios (Abril 2007), p. 7; Gómez Tomillo, Manuel, Derecho penal sexual y reforma legal. Análisis desde una perspectiva politico-criminal, en Revista Electrónica de Ciencia Penal y Criminología, 7 (2005) 4, pp. 34-35, disponible en http://criminet.ugr.es/recpc/07/recpc07-04.pdf, consultado con fecha 19 de octubre de 2014.

${ }^{7}$ Este planteamiento ha sido defendido en Chile por Vera Azócar, Alejandra - Sepúlveda SÁnchez, Ivonne, Aproximaciones a los bienes jurídicos protegidos y a las cuestiones concursales en el ámbito de los delitos vinculados a la pornografía infantil, en Revista Jurídica del Ministerio Público, 49 (Santiago, diciembre 2011), p. 198. Lo sostiene también Molina Cantillana, René, Delitos de pornografía infantil (Santiago, Librotecnia, 2008) pp. 58 ss., pero restringido a aquellos casos en que la víctima está consciente de que ha sido utilizada para la producción de material pornográfico; en caso contrario, lo protegido sería la intimidad del menor. 
específico, el artículo 366 quinquies CPen. está considerado dentro del párrafo $6^{\circ}$, bajo la rúbrica "Del estupro y otros delitos sexuales". En estas circunstancias, si el propio texto de la ley remite el delito que nos ocupa al ámbito de la criminalidad sexual, mal podría el intérprete reconducirlo a un ámbito distinto, como sería aquel donde se ubican los atentados contra el honor o contra la esfera de intimidad de las personas. Por ello, no cabe sino atribuirle el mismo fundamento que subyace a los delitos de violación, estupro y abuso sexual: el derecho de las personas a no verse involucradas en un contexto sexual en atención al daño físico, psíquico o emocional que tal experiencia puede ocasionar en el común de los seres humanos ${ }^{8}$. Entre las distintas fórmulas discursivas que la doctrina utiliza para expresar una idea como la indicada, pensamos que es posible utilizar indistintamente las nociones de indemnidad e integridad sexual, porque ambas aluden a valoraciones que se insertan de lleno en el campo de la sexualidad y, además, refieren a la necesidad de proteger al menor frente a hechos que pudieren dañar o entorpecer su desarrollo en ese plano. ${ }^{9}$

\section{Conducta punible.}

Desde la modificación introducida por la Ley N¹9.927, el artículo 366 quinquies CPen. sanciona al que "participare en la producción de material pornográfico, cualquiera sea su soporte, en cuya elaboración hubieren sido utilizados menores de dieciocho años". Pese a la complejidad de los términos en que aparece redactada la disposición, es claro que la conducta sancionada consiste simplemente en "producir" material pornográfico; ello en razón del imperativo constitucional de restringir el núcleo de cada delito a una conducta humana, exigencia que en términos gramaticales se materializa en un verbo. ${ }^{10}$ Producir, por su parte, de acuerdo con el Diccionario de la Real Academia Española significa, entre otras cosas, "elaborar", "fabricar" o "crear" una cosa, ${ }^{11}$ en este caso, material pornográfico en cuya realización hubieren sido utilizados menores de dieciocho años.

\footnotetext{
${ }^{8}$ Rodríguez Collao, Luis, Delitos sexuales (2a edición, Santiago, Editorial Jurídica de Chile, 2014), pp. 175- 176.

${ }^{9}$ Con más detalle sobre el punto, RodríGuez Collao, Luis - Mayer Lux, Laura: La conducta típica del delito de producción de pornografía infanto-juvenil, en Doctrina y Jurisprudencia Penal, 15 (U. de los Andes, 2013), pp. 25 ss.

${ }^{10}$ Artículo 19 № 3 inciso $8^{\circ} \mathrm{CPol}$., el cual dispone que "ningún delito se castigará con otra pena que la que señale una ley promulgada con anterioridad a su perpetración, a menos que una nueva ley favorezca al afectado".

${ }^{11}$ Véase las acepciones quinta y séptima de la voz "producir" en el Diccionario. Véanse, asimismo, Molina Cantillana, cit. (n. 7), p. 63; y Morillas Fernández, David, Análisis dogmático y criminológico de los delitos de pornografía infantil (Madrid, Dykinson, 2005), p. 261.
} 
Coincidente con esta forma de entender el vocablo "producir", la Ley $\mathrm{N}^{\circ}$ 19.846, sobre calificación de la producción cinematográfica, específicamente en el artículo 2, letra b), define producción cinematográfica como "la elaboración de imágenes en movimiento a través de cualquier soporte, con o sin sonido, independiente de su duración".

Queda claro, en consecuencia, que lo sancionado no es la realización de ciertas acciones de índole sexual con intervención del menor o su involucramiento en un contexto de actuación de ese mismo carácter -lo que eventualmente puede ser captado por otros tipos penales (por ejemplo, violación, estupro o abuso sexual)-, sino la elaboración de un registro de la actividad desplegada por el menor o de su cuerpo. Este registro, como lo reconoce el propio artículo 366 quinquies, inciso $2^{\circ} \mathrm{CPen}$., puede quedar plasmado en cualquier soporte, ya sea papel, magnético o digital; y la representación podrá consistir en fotografías, dibujos y grabaciones visuales o auditivas. ${ }^{12}$

La consumación se producirá, en consecuencia, tan pronto como quede perfeccionado el registro de los genitales (con fines primordialmente sexuales) del menor de edad o de la actividad sexual desplegada por el menor, es decir, cuando dicho registro está en condiciones de ser apreciado a través de los sentidos. No basta, en consecuencia, con la existencia del soporte si éste, por sí mismo, no permite comunicar a otros el contenido pornográfico para cuyo registro haya sido utilizado el menor de dieciocho años. ${ }^{13}$

\section{Autoría EN EL DELITO DE PRODUCCIÓN DE MATERIAL PORNOGRÁFICO INFANTO-JUVENIL}

\section{Autoría directa o inmediata.}

Es autor directo o inmediato quien ejecuta por sí mismo el hecho delictivo, ya sea en una parte o en su totalidad..$^{14}$ Respecto de quien ejecuta personalmente to do lo que el precepto demanda, la doctrina mayoritaria sostiene que el castigo se funda en el propio tipo penal, sin que sea necesario recurrir a las hipótesis del artículo $15 \mathrm{CPen} .{ }^{15}$ Pero también es autor

\footnotetext{
${ }^{12}$ Véase Molina Cantillana (n. 7), pp. 64-65.

${ }^{13}$ Rodríguez Collao - Mayer Lux, cit. (n. 9), pp. 25-42.

${ }^{14}$ Hay autores que consideran autor directo o inmediato sólo a quienes realizan “todos los presupuestos del tipo penal”. Así, por ejemplo, Hernández Basualto, Comentario al artículo 15 del Código Penal, en Hernández Basualto - Couso Salas, Código Penal comentado. Libro primero (arts. $1^{\circ}$ a 105) (Santiago, Abeledo Perrot, 2011), pp. 387-388.

${ }^{15}$ En este sentido se orientan las opiniones de Cury, Enrique, Derecho penal. Parte general, (10 edición, Santiago, Ediciones Universidad Católica de Chile, 2011),
} 
directo o inmediato el que simplemente to ma parte en la ejecución del hecho delictivo (sin realizarlo por completo), en cuyo caso el castigo se funda en lo que dispone el artículo $15 \mathrm{~N}^{\circ} 1 \mathrm{CPen}$. Esta forma de autoría parcial puede asumir dos formas: en la primera, el sujeto debe realizar actos inmediatos y directos; en la segunda, basta con que su intervención esté encaminada a impedir que se evite la consumación del delito. Pero ambas hipótesis quedan sometidas a la exigencia común de que el sujeto haya tomado parte en la ejecución del hecho, lo cual debe entenderse como una exigencia de que aquél haya realizado actos ejecutivos, en el sentido que fluye del artículo 7 CPen. ${ }^{16}$

Ejemplo de la primera situación descrita sería la actitud de quien filma con una cámara la mitad de las escenas de una secuencia pornográfica, mientras otro registra con una segunda cámara las escenas restantes. Ejemplo de la segunda situación sería el comportamiento de quien inmoviliza al menor que asume la calidad de víctima para que otro capte planos estrictamente genitales, con un fin primordialmente sexual, actuando positivamente para que este último no pueda defenderse, huir o comunicarse con otras personas.

\section{Autoria mediata.}

Según enseña Cury, autor mediato es "quien para ejecutar el hecho típico se sirve de otro, cuya voluntad domina, y que es quien lo realiza materialmente"17. Pese a que se discute ampliamente acerca del fundamento positivo de esta figura ${ }^{18}$, ella cuenta con un reconocimiento amplio res-

p. 597; Novoa Monreal, Eduardo, Curso de derecho penal chileno. Parte general (3a edición, Santiago, Editorial Jurídica, 2005), p. 183; y YÁñez Pérez, Sergio, Problemas básicos de la autoría y de la participación en el código penal chileno, en RivacoBA (director), Actas de las Jornadas Internacionales de Derecho Penal, en celebración del centenario de Código Penal chileno (Valparaíso, EDEVAL, 1975), p. 173. En España hace suyo este planteamiento, entre otros, Díaz y García Conlledo, Miguel, La autoría en Derecho Penal (Segunda Edición, Editorial Jurídica de Santiago, Santiago, 2011), p. 692. No comparte este parecer GARRIDO MonTt, cit. (n. 2), II, p. 303.

${ }^{16}$ En este sentido, YÁNEZ, cit. (n. 15), pp. 171-172.

${ }^{17}$ Cury, Enrique, Artículos 14 a 17 del Código Penal, en Politoff - Ortiz QuiROGa (directores), Texto y comentario del Código Penal chileno (Santiago, Editorial Jurídica de Chile, 2009), p. 239; Hernández Basualto, cit. (n. 14), p. 389.

${ }^{18}$ Algunos, como Cury, cit. (n. 17), p. 239, Politoff - Matus - Ramírez, cit. (n. 5), p. 398, e implícitamente Medina Jara, Rodrigo, Código Penal. Doctrina y jurisprudencia (Santiago, Puntolex - Thompson Reuters, 2010), p. 80, señalan que está contemplada en el artículo $15 \mathrm{~N}^{\circ} 2$, en tanto allí se castiga a quien fuerza a otro a ejecutar un delito; otros, como GarRido MonTt, cit. (n. 2), II, p. 306, que la incorporan entre las hipótesis abarcadas por el $\mathrm{N}^{\circ} 1$ del mismo precepto e incluso quienes, como Novoa Monreal (n. 15), p. 161, le restan independencia, señalando 
pecto de su status dogmático como forma autónoma de autoría, siendo importante recalcar que lo medular de la figura consistirá en que al sujeto actuante o instrumento, pese a tener aptitud para realizar la conducta, queda exento de responsabilidad penal. ${ }^{19}$

La autoría mediata, por cierto, tiene plena vigencia y aplicación respecto del delito de producción de material pornográfico infanto-juvenil. Para determinar el sustrato fáctico de esta figura, es preciso distinguir según si la persona que asume la condición de autor mediato se vale de un menor de edad o de un adulto. En el primer caso, a su vez, habrá que diferenciar entre el aprovechamiento de un menor de catorce años y el de una persona mayor de catorce, pero menor de dieciocho años.

Ciertamente el hecho de obtener que un menor de catorce años efectúe un registro de sí mismo en un contexto pornográfico, a instancias de un sujeto imputable convierte per se a este último en autor mediato, porque el ordenamiento jurídico parte de la base de que el primero no está jurídicamente capacitado para consentir válidamente la realización de actos con contenido o significación sexual, de modo que cualquier interacción con él en este plano ha de considerarse intrínsecamente abusiva. Sería ésta una hipótesis de autoría mediata por autolesión del instrumento ${ }^{20}$, que se funda en las propias valoraciones que contiene el ordenamiento, particularmente en los artículos 362 y 366 bis CPen.

Tratándose de una persona mayor de catorce años, pero menor de dieciocho años, cabe tener en cuenta que dentro de los límites de este segmento etario, la actividad sexual que el adolescente ejecute es lícita, salvo cuando él es víctima del actuar violento o abusivo de otra persona. En consecuencia, el hecho de obtener que un menor dentro de estos márgenes de edad efectúe un registro de sí mismo en un contexto pornográfico, a instancias de un sujeto imputable no convierte automáticamente a éste en autor mediato, salvo que aproveche alguna circunstancia concurrente, como el hecho de que el menor padezca algún trastorno psíquico o que se haya utilizado en contra de él alguna forma de coacción. Pero en este caso, lo determinante para que estemos frente a un caso de autoría mediata no sería la edad de la persona instrumentalizada, sino su falta de libertad o de lucidez mental.

que los supuestos a los que se les atribuye esta calidad quedan de hecho subsumidos en el concepto de autor sin otro complemento.

${ }^{19}$ Cfr. Hernández Basualto, cit. (n. 14), p. 389; y Mañalich raffo, Juan Pablo, La estructura de la autoría mediata, en Revista de Derecho de la Pontificia Universidad Católica de Valparaíso, 34 (2010, semestre I), p. 392.

${ }^{20}$ Hipótesis a la que se refieren: Cury, cit. (n. 17), p. 240, Mañalich, cit. (n.19), p. 405; y Politoff - Matus - Ramírez, cit. (n. 5), p. 401. 
Por último, respecto de la persona mayor de dieciocho años la situación es prácticamente la misma que la del adolescente mayor de catorce, teniendo cabida respecto de aquél todas las formas de instrumentalización que dan lugar a la categoría del autor mediato.

\section{Coautoría del artículo $15 N^{\circ} 3$ CPen.}

En términos amplios, la doctrina considera coautores a quienes ejecutan colectivamente un delito, existiendo un acuerdo de voluntades entre todos ellos y un aporte funcional de su parte a la ejecución del hecho común. ${ }^{21}$ En la actualidad es ampliamente mayoritaria la opinión que sostiene que la coautoría se encuentra regulada fundamentalmente en el artículo $15 \mathrm{~N}^{\circ}$ 3 CPen., que considera autores a quienes, "concertados para su ejecución, facilitan los medios con que se lleva a efecto el hecho o lo presencian sin tomar parte inmediata en él". Esta forma de entender el precepto, que consideramos en líneas generales correcta, demanda en consecuencia no sólo un acuerdo de voluntades, sino la existencia de un aporte funcional, lo que se traduce en el requerimiento de una contribución esencial o decisiva para la consumación del delito. ${ }^{22}$

Muy discutible es, a este respecto, la posibilidad de sancionar como coautor al fin ancista o productor del material en sentido cinematográfico, esto es, al individuo que, con responsabilidad financiera y comercial, organiza la realización del material pornográfico infanto-juvenil, aportando el capital necesario para su elaboración. ${ }^{23}$ La decisión acerca de si debe ser castigado como cómplice, en cuanto coopera a la ejecución del hecho, o como coautor, dependerá no sólo de que exista concier to, sino de que su aporte sea realmente esencial o decisivo y de que se concrete en la etapa de ejecución o elaboración del material y no en un momento posterior (referido, por ejemplo a la reproducción, difusión, transporte o comercialización del mismo).

${ }^{21}$ Ver, por todos, Hernández Basualto, cit. (n. 14), p. 399.

${ }^{22}$ Así, por ejemplo, Bullemore, Vivian - MacKinnon, John, Curso de derecho penal (Santiago, LexisNexis, 2007), II, p. 127; HernándeZ BASUAlto, cit. (n. 14), p. 403; Mañalich, cit. (n.19), p. 477; y Soto Piñeiro, Miguel, La noción de autor en el Código Penal chileno, en Gaceta Jurídica, 68 (1986), pp. 49-53.

${ }^{23}$ Así, la tercera acepción de la voz "productor" contenida en el Diccionario. En la legislación española, la conducta consistente en financiar la elaboración de material pornográfico está sancionada de manera autónoma en el artículo 189, surgiendo la duda en la doctrina respecto si ese financiamiento se podría traducir en la aportación de medios evaluables en dinero (v.gr. la cámara) o sólo consistiría en una aportación monetaria, inclinándose por éste último supuesto, siendo punible la otra opción por las reglas de la participación y específicamente, la de complicidad, así en GÓmEZ Tomillo, Manuel, cit. (n. 6), p. 27. 


\section{Participación EN El Delito}

DE PRODUCCIÓN DE MATERIAL PORNOGRÁFICO INFANTO-JUVENIL

\section{Admisibilidad de la participación.}

La posibilidad de castigar a quien interviene como partícipe en el delito de producción de material pornográfico infanto-juvenil ha sido puesta en duda por algunos autores, básicamente en atención a que el tipo aparece estructurado sobre la base del verbo "participar" (en la elaboración de material pornográfico), cuya amplitud de contenido permitiría captar no sólo las hipótesis clásicas de autoría, sino también algunas formas de participación. En otras palabras, los términos que utiliza la ley para describir este delito implicarían una equiparación del autor y el partícipe, en cuanto a la pena aplicable, porque tanto aquél como éste, en definitiva, participarían en la producción de aquel material. ${ }^{24}$

Es muy probable que la intención del legislador al tipificar la conducta fuera sancionar a autores y a partícipes con igual penalidad, pero hay argumentos literales, teleológicos y sistemáticos que obligan a atribuir a la expresión un sentido mucho más acorde con los grandes principios rectores del sistema penal, especialmente con las ideas de responsabilidad personal, culpabilidad y proporcionalidad.

En efecto, el artículo 14 CPen. dispone que "son responsables criminalmente de los delitos: los autores, los cómplices y los encubridores". Frente a una disposición tan categórica como ésta, sólo cabría restringir el alcance de la misma en dos casos: $i$ ) cuando el Código (u otra ley en su reemplazo) estableciera una excepción para uno o más delitos determinados; y ii) cuando la propia naturaleza de la conducta incriminada fuera incompatible con una diferenciación entre autores y partícipes. En relación con lo primero, no existe en este caso una excepción expresamente establecida para el delito de producción de material pornográfico infanto-juvenil, por lo que sólo restaría indagar si la conducta sancionada es o no compatible con una tal diferenciación. En relación con esto último, ya hemos explicado que la conducta típica debe ser entendida como producir material pornográfico infanto-juvenil -lo cual significa confeccionar, elaborar o fabricar dicho material- y en el desarrollo de esta actividad es perfectamente concebible y admisible distinguir entre intervinientes que desempeñan un papel principal y otros que juegan un rol secundario o accesorio, de modo que

${ }^{24}$ Tal es el planteamiento de Matus Acuña, Jean Pierre - Ramírez GuZmán, María Cecilia, Lecciones de derecho penal chileno. Parte especial (3a edición, Santiago, La Ley, 2014), I, p. 352, al menos respecto de la complicidad, que, según su opinión, ha sido equiparada a la autoría en cuanto a la pena aplicable. 
tampoco en este sentido cabe afirmar la necesidad de equiparar al autor y al partícipe.

Pero la verdad es que el propio Código Penal ofrece un argumento adicional a favor de la tesis que aquí se sustenta. El artículo 371 de dicho cuerpo legal, en efecto, dispone que "los ascendientes, guardadores, maestros y cualesquiera personas que con abuso de autoridad o encargo, cooperaren como cómplices a la perpetración de los delitos comprendidos en los dos párrafos precedentes, serán penados como autores”. Este artículo en realidad consagra una circunstancia agravante que afecta a determinadas personas que intervinieren como cómplices de algunos delitos -entre los que se cuenta el de producción de material pornográfico infanto-juvenil- y la agravación consiste, precisamente, en que la pena aplicable pasa a ser aquella que corresponde a los autores. Con ello, la disposición reconoce implícitamente que en el resto de los casos el cómplice debe ser castigado como tal.

\section{La instigación.}

En primer término, no produce ni toma parte en la producción, y por lo mismo es partícipe y no autor, quien induce o instiga a otro a elaborar pornografía infanto-juvenil, es decir, quien forma en otro de manera directa la decisión de producir el material, esto porque el designio de tomar parte en la producción se forma en la mente de un sujeto distinto del instigador, careciendo este último de las notas de autonomía y poder de decisión propias de la autoría ${ }^{25}$.

No afecta a la conclusión anterior el hecho de que el instigador aparezca contemplado en el artículo 15 CPen., porque esta disposición no dice que aquél sea autor, sino simplemente que ha de ser considerado como tal, lo cual sólo tiene proyecciones en el ámbito de la determinación de la pena, pero no muda la naturaleza de la inducción o instigación en cuanto forma de intervenir en un hecho delictivo.

\section{La complicidad.}

De acuerdo con lo que dispone el artículo 16 CPen., hemos de considerar como cómplice a quien coopera a la producción de material pornográfico infanto-juvenil, sin intervenir directamente en el desarrollo de esta actividad, por actos anteriores o simultáneos. Quedan incluidas aquí, por ejemplo, las personas que colaboran con el autor proporcionándoles las cámaras, los soportes de registro, los equipos de audio e iluminación,

${ }^{25}$ Hernández Basualto, cit. (n. 14), p. 389; Novoa Monreal, cit. (n. 15), pp. 168-169. 
las imágenes inocuas, los programas de edición y hasta la locación donde se lleva a cabo el registro, entre varias otras formas de auxilio imaginables.

Como ya hemos adelantado, la delimitación entre esta figura y aquella que contempla el artículo 15 No 3 CPen., ha de ser efectuada tomando en consideración dos aspectos: primero, la existencia o no de concierto entre los intervinientes, referido a la ejecución de la conducta delictiva $\mathrm{y}$, segundo, que el aporte del sujeto sea determinante o esencial en el proceso de producción del material pornográfico infanto-juvenil. Faltando cualquiera de estas dos condiciones, el interviniente ha se ser considerado como cómplice. Esta es la razón por la cual consideramos que el productor o financista del material pornográfico debe ser castigado como tal, salvo que se demuestre que su intervención fue decisiva e insustituible para la obtención de aquel material, en cuyo caso asume la calidad jurídica de autor.

\section{Accesoriedad de la instigación y de la complicidad.}

Sabido es que en el ordenamiento jurídico chileno la participación tiene un indiscutible carácter secundario o accesorio, de acuerdo con el cual el castigo de la instigación y de la complicidad se encuentra supeditado a que el autor efectivamente llegue a dar comienzo a la ejecución del delito, a través de actos externamente apreciables y susceptibles de ser calificados, al menos, como tentativa. El carácter accesorio de la participación implica también una exigencia relativa a la calidad jurídica del hecho principal que, entre nosotros, por razones que no es del caso desarrollar aquí, se traduce en la necesidad de que el autor haya ejecutado un acto típico y antijurídico. ${ }^{26}$

A propósito de la extensión de la complicidad y de la instigación en el delito aquí estudiado, se presenta un problema muy relevante a raíz de lo establecido por el artículo $4^{\circ}$ de la Ley $\mathrm{N}^{\circ} 20.084$, sobre Responsabilidad penal de adolescentes. Dicho artículo dispone: "No podrá procederse penalmente respecto de los delitos previstos en los articulos 362, 365, 366 bis, 366 quáter y 366 quinquies del Código Penal, cuando la conducta se hubiere realizado con una persona menor de catorce años y no concurra ninguna de las circunstancias enumeradas en los artículos 361 ó 363 de dicho Código, según sea el caso, a menos que exista entre aquélla y el imputado una diferencia de, a lo menos, dos años de edad, tratándose de la conducta descrita en el artículo 362, o de tres años en los demás casos". La incorporación del artículo 366 quinquies a esta disposición operó mediante la Ley $\mathrm{N}^{\circ} 20.526$ y genera un supuesto muy conflictivo que puede ser ilustrado con el siguiente ejemplo:

${ }^{26}$ La doctrina deduce esta exigencia del propio tenor de los artículos 15 y 16 CPen., los cuales no aluden a intervenir en un "delito", sino en un "hecho". Ver, por todos, CURY, cit. (n. 15), p. 641. 
un joven de quince años mantiene relaciones sexuales con su pareja, una niña de trece años, y al mismo tiempo capta la escena con una cámara de video. Los hechos ocurren en un lugar que fue proporcionado por un amigo de ambos: un joven de dieciséis años, quien estaba perfectamente enterado de todo lo que ocurriría, quien además les presta la cámara con que se lleva a cabo el registro de las imágenes.

Para determinar si el amigo -cuya intervención indudablemente ha de ser calificada como complicidad respecto de la producción de material pornográfico-incurre o no en responsabilidad es preciso indagar, en primer término, acerca de la naturaleza jurídica de la disposición que contiene el artículo 4 L. de resp. penal adolesc. Al respecto, las opiniones se dividen entre la de aquellos que sostienen que la ausencia de castigo se basa en el hecho de no haberse configurado el delito ${ }^{27}$ y la de quienes afirman que estamos en presencia de una excusa legal absolutoria. ${ }^{28}$ De aceptarse la primera posición, desde luego, no sería posible el castigo de quien interviene como partícipe, atendido el carácter unitario de la tipicidad y de la antijuridicidad; ello, en cambio, sí sería posible en caso de aceptarse el segundo criterio, en razón del carácter eminentemente personal de las excusas legales absolutorias.

Nos inclinamos por la primera posición. El precepto en estudio no contiene ninguna referencia de la cual inferir que el fundamento de la exención de pena está vinculado con razones de conveniencia o de oportunidad del castigo, que es lo propio de una excusa legal absolutoria. Antes bien, el hecho de que tal exención sea improcedente en caso de haberse utilizado alguna de las modalidades ejecutivas previstas en los artículos 361 ó 363, pone de manifiesto que el fundamento se vincula con la intensidad del ataque al bien jurídico y con la magnitud de las consecuencias del comportamiento sexual abusivo.

Por otra parte, al formular la exigencia de una asimetría de edad, el legislador se hizo eco de un criterio definitorio de la noción de abuso sexual infantil que alcanzó gran difusión durante la década de los años

${ }^{27}$ De esta opinión, entre otros, HeRnández BASUALTo, El nuevo derecho penal de adolescentes y la necesaria revisión de su teoría del delito, en Revista de Derecho de la Universidad Austral de Chile, 20 (Valdivia, 2007) 2, pp. 195-217.

${ }^{28}$ Así, entre otros, Aguilar Aranela, cit. (n. 3), p. 64; Carrasco Jiménez, Edison, Aspectos y problemas del delito de violación (Santiago, Librotecnia 2010).pp. 7998; y Oxman Vilches, N., Consideraciones críticas en torno al artículo $4^{\circ}$ de la Ley $N^{\circ}$ 20.084, en FERNÁNDEZ CRUZ (coordinador) Estudios de ciencias penales, hacia una racionalización del Derecho penal (Santiago, 2008); y SANTiBÁÑEZ TORRES, María Elena - PeÑa Wasaff, Silvia, Comentarios sobre el art. $4^{\circ}$ de la Ley 20.084, en Boletín del Ministerio Público, 25 (2005), p. 255. 
noventa y comienzos de la década siguiente. Según dicho criterio, el elemento esencial de la noción de abuso sexual es el aprovechamiento de una posición dominante respecto de la víctima. Este requisito, en el caso del abuso sexual infantil, se plantea conjuntamente (y en un sentido de interdependencia) con el de una asimetría de edad entre el autor y la víctima, en el sentido de que el primero sea mayor que la segunda y que lo sea por un lapso que muchos fijan en cinco años como mínimo. ${ }^{29}$ Esto obedece, según algunas opiniones, a que "la asimetría de edad impide la verdadera libertad de decisión y hace imposible una actividad sexual común, ya que los participantes tienen experiencias, grado de madurez biológica y expectativas muy diferentes"; de lo cual se llega a inferir que "esta asimetría supone en sí misma un poder que vicia toda posibilidad de relación igualitaria" ${ }^{30} \mathrm{En}$ definitiva, un acto será abusivo cuando el ofensor tenga un conocimiento más sofisticado sobre el alcance y las implicaciones del encuentro sexual, lo cual puede fundarse no sólo en una mayor experiencia, sino también en un mayor desarrollo de la capacidad intelectual ${ }^{31}$.

Si tal es el fundamento de la diferencia de edad que exige el tipo, no cabe duda de que ella se vincula con la inexistencia de una relación verdaderamente abusiva entre las personas que están dentro de esos márgenes, y no con la inconveniencia o inoportunidad de la aplicación de la pena. Es posible, en consecuencia, afirmar que la diferencia de edad entre autor y víctima es en estos delitos un elemento fundante de la ilicitud, pero no de su punibilidad ${ }^{32}$. Con esto presente, y volviendo al ejemplo propuesto, la conducta del amigo debería quedar impune, por cuanto el autor no ha llegado al estándar de conducta típica y antijurídica, que demanda el criterio de accesoriedad media imperante en el ordenamiento jurídico chileno.

\section{El encubrimiento.}

Como es sabido, abundan las opiniones que plantean la necesidad de

${ }^{29}$ Cfr. Berlinerblau, Virginia, Abuso sexual infantil, en Lamberti - SÁnChez - Viar (compiladores), Violencia familiar y abuso sexual (Buenos Aires, Editorial Universidad, 1998), pp. 90-91. En un sentido análogo, TAmarit Sumalla, La protección penal del menor frente al abuso y la explotación sexual (2a edición, Pamplona, Aranzadi, 2002), pp. 20-22.

${ }^{30}$ En este sentido, López Sánchez, Félix - Hernández, Amparo - Carpintero, Eugenio, Los abusos sexuales de menores: concepto, prevalencia y efectos, en Infancia y Aprendizaje, 71 (U. de Salamanca, 1995), p. 80.

${ }^{31}$ Cfr. Coulborn, Katheline, Child Sexual Abuse: Intervention and Treatment Issues, en Child Abuse \& Neglect (1993), pp. 4-6.

${ }^{32}$ Con consecuencias análogas a las que aquí se proponen, Hernández BasualTO, cit. (n. 27), pp. 195-217, plantea la diferencia de edad como un elemento objetivo del tipo, cuya ausencia opera como causal de atipicidad. 
concebir el encubrimiento como un delito autónomo, cuyo fundamento no sería la protección del mismo bien jurídico afectado por la conducta del autor, sino derechamente la correcta administración de justicia. ${ }^{33}$ Pese a ello, frente a la tajante declaración del artículo 14 CPen. y a la regulación que contienen los tres artículos siguientes, no cabe ninguna duda en orden a que -con base en el ordenamiento jurídico chileno- el encubridor debe ser tratado y sancionado como partícipe del delito en que hubiere intervenido.

Asumiendo este planteamiento, cabe recordar que el encubridor participa en una etapa del íter delictual posterior a la consumación del delito, es decir, la intervención de aquél sólo se explica una vez que ya se han realizado las acciones que integran el tipo, lo cual se obtiene de la propia literalidad de los artículos 15, 16 y 17 CPen., en cuanto los dos primeros aluden a hechos, mientras que el último derechamente hace referencia a "Crímenes o simples delitos".

De este modo, centrándonos en el delito que motiva estos comentarios, es ineludibe determinar el instante en que finaliza la ejecución del mismo y comienza el encubrimiento, lo cual sucede, como ya hemos adelantado, tan pronto como queda perfeccionado el registro de los genitales (con fines primordialmente sexuales) del menor de edad o de la actividad sexual desplegada por éste, es decir, cuando dicho registro está en condiciones de ser apreciado a través de los sentidos. De esta forma, las labores de edición, musicalización, depuración de imagen o sonido sobre el soporte ya producido y otras análogas quedan fuera de la tipicidad de la conducta por cuanto se trata de comportamientos que ocurren con posterioridad al momento en que el delito alcanzó la consumación.

Sin embargo, al tenor de lo dispuesto por el artículo 17 CPen. el factor temporal no basta para calificar cualquier intervención posterior al hecho como encubrimiento: ello sólo ocurrirá cuando la intervención del sujeto asuma alguna de las formas que el Código expresamente prevé, es decir, aprovechamiento y favorecimiento (sea éste ocasional o real) ${ }^{34}$. Sin entrar en un estudio completo de cada una de estas situaciones, interesa aquí poner de relieve algunas situaciones que pueden llegar a ser conflictivas respecto del delito de producción de material pornográfico infanto-juvenil.

Como se sabe, el aprovechamiento está contemplado en el artículo 17 CPen. en los siguientes términos: "Son encubridores los que con conocimiento de la perpetración de un crimen o simple delito o de los actos ejecutados para llevarlos a cabo, sin haber tenido participación en él como autores ni como

${ }^{33}$ Así, Etcheberry, Alfredo, Derecho penal. Parte general (3 $3^{a}$ edición, Santiago, Editorial Jurídica de Chile, 1998), II, p. 80; CurY, cit. (n. 15), p. 630.

${ }^{34}$ Ver, por todos, Bullemore - MacKinnon, cit. (n. 22), p. 186. 
cómplices, intervienen con posterioridad a su ejecución de alguno de los modos siguientes: $1^{\circ}$ Aprovechándose por sí mismos o facilitando a los delincuentes medios para que se aprovechen de los efectos del crimen o simple delito". Conforme a esta redacción, la hipótesis implica que el encubridor debe disfrutar de los efectos del delito, o bien, facilitar los medios a los autores o a los cómplices del delito para que procedan de igual modo ${ }^{35}$; todo ello, en el entendido de que por efectos del delito, la disposición alude al objeto material del mismo ${ }^{36}$, y que la conducta de aprovechar acostumbra ser interpretada como sinónimo de obtener un beneficio pecuniario ${ }^{37}$.

Bajo estas condiciones se podría hablar de un aprovechamiento por receptación del delito de producción de material pornográfico infanto-juvenil si, por ejemplo, una vez captado el material se le cede a otro su tenencia para que lo venda. Sin embargo, no debemos olvidar que esa misma conducta parece estar comprendida igualmente en el artículo 374 bis $\mathrm{CPen}$. inciso $1^{\circ}$, por cuanto ahí se sanciona a quien comercialice material pornográfico, cualquiera sea su soporte, en cuya elaboración hayan sido utilizados menores de dieciocho años. Nos parece claro que en la situación descrita no estamos frente a un concurso de delitos, porque si bien formalmente es posible distinguir dos títulos de imputación (encubrimiento de producción de material pornográfico y autoría de difusión de ese mismo material), en el plano valorativo estamos frente a un solo hecho que representa una sola entidad tanto desde la perspectiva del desvalor de acción y de resultado, como desde el punto de vista de la necesidad de la intervención penal. Se trata, en consecuencia, de un concurso aparente de leyes penales cuya solución debe buscarse en la aplicación del criterio de la subsidiariedad, primando, por cierto, la figura contemplada en el artículo 374 bis CPen. ${ }^{38}$ De no ser así, la hipotética preeminencia del castigo a título de encubrimiento del delito de producción de material pornográfico infanto-juvenil tornaría en ilusoria la posibilidad de sancionar las conductas incluidas en la disposición aludida, tornando en superflua su tipificación.

${ }^{35}$ Garrido MontT, cit. (n. 2), II, p. $3^{03}$.

${ }^{36}$ Cury Urzúa, cit. (n. 17), p. 252; EtCheberry, cit. (n. 33), II, p. 103.

${ }^{37}$ Bullemore - MacKinnon, cit. (n. 22), p. 186; Politoff - Matus - Ramírez, cit. (n. 5), p. 433.

${ }^{38}$ No vemos aquí una relación de especialidad, porque en estricto rigor ninguna de las dos figuras en conflicto contiene la totalidad de los elementos exigidos por la otra. 


\section{BiBLIOGRAFíA}

Aguado López, Sara, Delitos contra la libertad e indemnidad sexuales, en Boix Reig, Javier (director), Derecho penal. Parte especial (Madrid, Iustel, 2010), I.

Aguilar Aranela, Cristián, Delitos sexuales (2a edición, Santiago, Editorial Metropolitana, 2012).

Berlinerblau, Virginia. Abuso sexual infantil, en Lamberti - Sánchez - Viar (compiladores), Violencia familiar y abuso sexual. (Buenos Aires, Editorial Universidad, 1998).

Bullemore, Vivian - MacKinnon, John, Curso de derecho penal, (2 a edición, Santiago, LexisNexis, Chile, 2007).

Caruso Fontán, María Viviana, Nuevas perspectivas sobre los delitos contra la libertad sexual (Valencia, Tirant Lo Blanch, 2011).

Carnevali Rodríguez, Raúl, Algunas precisiones respecto de los delitos de producción de material pornográfico infantil, de favorecimiento de prostitución de menores y de obtención de servicios sexuales (Informe en derecho $N^{\circ} 2$, Defensoría Penal Pública, Departamento de Estudios, Santiago, 2012).

Carrasco Jiménez, Edison, Aspectos y problemas del delito de violación (Santiago, Librotecnia 2010).

Coulborn, Katheline, Child Sexual Abuse, Intervention and Treatment Issues, en Child Abuse \& Neglect (1993).

Cox LeiXlard, Juan Pablo, Los delitos de producción, adquisición y tenencia maliciosa de material pornográfico como figuras expansivas del Derecho penal, en Revista de Derecho de la Pontificia Universidad Católica de Valparaiso, 26 (2005, Semestre I).

Cury, Enrique, Derecho penal. Parte general (10a edición, Santiago, Ediciones Universidad Católica de Chile, 2011).

Cury, Enrique, Artículos 14 a 17 del Código Penal, en Politoff - Ortiz Quiroga (directores), Texto y comentario del Código Penal chileno (Santiago, Editorial Jurídica de Chile, 2009).

De La Fuente Jiménez, Claudia, Delitos de pornografía infantil (Santiago, Legal Publishing, 2008).

De La Rosa Cortina, José Miguel, Los delitos de pornografía infantil. Aspectos penales, procesales y criminológicos (Valencia, Tirant Lo Blanch, 2011).

Díaz y García Conlledo, Miguel, La autoría en derecho penal (2a edición, Santiago, Editorial Jurídica de Santiago, 2011).

Etcheberry, Alfredo, Derecho penal. Parte general (3a edición, Santiago, Editorial Jurídica de Chile, 1998), II.

FERNÁNDEZ Teruelo, Javier, Derecho penal e internet. Especial consideración de los delitos que afectan a jóvenes y adolescentes (Valladolid, Lex Nova, 2011).

García Moretó, Estanislao, Problemas técnicos de la imagen digital en pornografía, en Revista del Instituto de Investigación en Criminología y Ciencias Penales de la Universidad de Valencia, (2009), pp. 51-59 (consultado con fecha 19 de abril de 2015, en http, //www.uv.es/recrim/recrim09/recrim09n04.pdf2

Garrido Montt, Mario, Derecho penal. Parte general ( $3^{a}$ edición, Santiago, Editorial Jurídica de Chile, 2003), II.

Garrido Montt, Mario, Derecho penal. Parte especial (4a edición, Santiago, Editorial Jurídica de Chile, 2010)

Derecho penal. Parte general, Etapas de ejecución del delito. Autoría y participación (Santiago, Editorial Jurídica de Chile, 1984). 
Gómez Tomillo, Manuel, Derecho penal sexual y reforma legal. Análisis desde una perspectiva politico-criminal, en Revista Electrónica de Ciencia Penal y Criminología, 7 (2005) 4, consultado con fecha 19 de abril de 2015, en http, //criminet.ugr.es/ recpc/07/recpc07-04.pdf,

Hernandez Basualto, Héctor, Comentario al artículo 15 del Código Penal, en Hernández Basualto - Couso Salas, Código Penal comentado. Libro primero (arts. $1^{\circ}$ a 105) (Santiago, Abeledo Perrot, 2011).

Hernández Basualto, Héctor, El nuevo derecho penal de adolescentes y la necesaria revisión de su teoría del delito, en Revista de Derecho de la Universidad Austral de Chile, 20 (Valdivia, 2007) 2.

Inostroza Díaz, Félix - Maffioletti Celedón, Francisco - Car Silva, Macarena, ¿Qué es el "grooming" o ciberacoso sexual a niños a través de internet? en Revista Jurídica del Ministerio Público, 35 (julio, 2008).

KüNSEMUller, Carlos, Derecho penal y politica criminal (Santiago, LegalPublishing, 2012).

López Sánchez, Félix - Hernández, Amparo - Carpintero, Eugenio, Los abusos sexuales de menores. Concepto, prevalencia y efectos, en Infancia y Aprendizaje, 71 (U. de Salamanca, 1995).

Mañalich Raffo, Juan Pablo, La estructura de la autoría mediata, en Revista de Derecho de la Pontificia Universidad Católica de Valparaíso, 34 (2010, semestre I).

Matus Acuña, Jean Pierre - Ramírez Guzmán, María Cecilia, Lecciones de derecho penal chileno. Parte especial (3a edición, Santiago, La Ley, 2014).

Medina Jara, Rodrigo (director), Código Penal. Doctrina y jurisprudencia (Santiago, Puntolex - Thompson Reuters, 2010).

Molina Cantillana, René, Delitos de pornografía infantil (Santiago, Librotecnia, 2008).

Morillas Fernández, David, Análisis dogmático y criminológico de los delitos de pornografía infantil (Madrid, Dykinson, 2005).

Novoa Monreal, Eduardo, Curso de derecho penal chileno. Parte general (3a edición, Santiago, Editorial Jurídica de Chile, 2005).

Oxman Vilches, Nicolás, Libertad sexual y Estado de Derecho en Chile (Santiago, Librotecnia, 2007).

Oxman Vilches, Nicolás, Consideraciones críticas en torno al artículo $4^{\circ}$ de la Ley $N^{\circ}$ 20.084, en FERNÁNDEZ CRUZ (coordinador), Estudios de ciencias penales, hacia una racionalización del derecho penal (Santiago, LegalPublishing, 2008).

Orts Berenguer, Enrique - Roig Torres, Margarita, Concepto de material pornográfico en el ámbito penal, en Revista del Instituto Universitario de Investigación en Criminología y Ciencias Penales de la Universidad de Valencia (disponible en http, //www.uv.es/recrim/recrim09/recrim09i01.pdf consultado con fecha 19 de octubre de 2014).

Politoff, Sergio - Matus Acuña, Jean Pierre - Ramírez Guzmán, María Cecilia, Lecciones de derecho penal chileno. Parte especial (2a edición, Santiago, Editorial Jurídica de Chile, 2005).

Politoff, Sergio - Matus Acuña, Jean Pierre - Ramírez Guzmán, María Cecilia, Ramos VÁsquez, José Antonio, El nuevo delito de ciberacoso de menores a la luz del derecho comparado, en Diario Ley (7746, Sección Doctrina, 29 de noviembre de 2011, Año XXXII). 
Rodríguez Collao, Luis, Delitos sexuales (2a edición, Santiago, Editorial Jurídica de Chile, 2014).

Rodríguez Collao, Luis - Mayer Lux, Laura, La conducta típica del delito de producción de pornografía infanto-juvenil, en Doctrina y Jurisprudencia Penal, 15 (U. de Los Andes, 2013), número monográfico sobre delitos sexuales.

Santibánez Torres, María Elena - Peña Wasaff, Silvia, Comentarios sobre el art. $4^{\circ}$ de la Ley 20.084, en Boletín del Ministerio Público, 25 (2005).

Serrano Gómez, Alfonso - Serrano Maíllo, Alfonso, Derecho penal. Parte especial (16 a edición, Madrid, Dykinson, 2011).

Soto Piñeiro, Miguel, La noción de autor en el Código Penal chileno, en Gaceta Jurídica, 68 (1986).

TAMARIT SumAlla, José María, La protección penal del menor frente al abuso y la explotación sexual (2a edición, Pamplona, Aranzadi, 2002).

Úbeda de los Cobos, Julio, La persecución de la pornografia infantil. Problemas relacionados con su distribución por Internet, en La Ley Penal, 37, Sección Estudios (Abril 2007).

Vera Azócar, Alejandra - Sepúlveda Sánchez, Ivonne, Aproximaciones a los bienes jurídicos protegidos y a las cuestiones concursales en el ámbito de los delitos vinculados a la pornografía infantil, en Revista Jurídica del Ministerio Público, 49 (Santiago, diciembre 2011).

YÁñez Pérez, Sergio, Problemas básicos de la autoría y de la participación en el Código Penal chileno, en Rivacoba (director), Actas de las Jornadas Internacionales de Derecho Penal, en celebración del centenario de Código Pena chileno (Valparaíso, EDEVAL, 1975). 